PESHAWAR JOURNAL OF PSYCHOLOGY AND BEHAVIORAL SCIENCES, 2018, VOL. 4, NO. 1, 1-13

\title{
Effects of Perceived Parenting Styles on Disruptive Behavior among Adolescents
}

\author{
Fehmida Shehzadi ${ }^{1}$, Ruqia Safdar Bajwa ${ }^{2}$, \\ Iram Batool ${ }^{3}$, \\ Bahauddin Zakariya University, Multan
}

\author{
and \\ Asghar Ali Shah ${ }^{4}$ \\ Islamic International University Islamabad
}

Adolescence is a very crucial stage of development. In order to determine the effect of perceived parenting styles on disruptive behavior, this study was planned to conduct among adolescents. The sample consisted of 120 adolescents who were taken from Multan City by using Purposive sampling technique. Parenting styles scale developed by Jody Powell (1990) and Beck Disruptive Behavior Inventory developed by Beck (2005) were used to assess perceived parenting styles and disruptive behavior respectively. The results indicated that there was a negative correlation between parenting styles and disruptive behavior. Results also showing the significant difference among male and female adolescence disruptive behavior and also defined that there is no significant difference in disruptive behavior among rural and urban adolescence. More studies should be conducted on this issue because it is important to enhance the positive child rearing practices in order to avoid problems in later life.

Keywords: parenting styles, disruptive behavior and adolescence.

\footnotetext{
${ }^{1}$ Department of Applied Psychology, Bahauddin Zakariya University, Multan ${ }^{2}$ Department of Applied Psychology, Bahauddin Zakariya University, Multan ${ }^{3}$ Assistant Professor, Department of Applied Psychology, Bahauddin Zakariya University, Multan Corresponding Author: i.batool@bzu.edu.pk

${ }^{4}$ Assistant Professor, Department of Applied Psychology, Islamic International University Islamabad
}

ISSN 2415-6779 EISSN 2518-4474

https://doi.org/10.32879/picp.2018.4.2.1

www.pjpbsicp.com 
Parenting styles are psychological standard representation that parents used for their children rearing. There are many different level of times and efforts which parent use in child rearing (Kopko, 2007). Parents adopt various combinations of temperament, through which children's personalities develop and it depends on parents- children interaction (Adarson, 1999). Diana offered four styles of parenting (i) authoritarian (ii) indulgent (iii) authoritative (iv) negligent. According to Fieldman (2005) childhood education has a great influence on child's personality. Piaget's told how child gets cognition through practices explores to the world. Erikson (1963) explained in more detail the cognitive development of the child in eight stages. Sociologist Frank Furedi, (2001) says that parent behavior has less impact on child's personality. Children have the capacity to develop their personalities in all circumstances. Parent temperament towards their children is the results of the behavior of their parents which they got from genetics.

\section{Baumrind's four general parenting styles}

Diana found four points which could be helpful in parenting style (i) Responsiveness vs. unresponsiveness and (ii) demanding vs. undemanding. Baumrind says that parents should not be at distance from their children inspire of that parents should be love for the children (Baumrind, 1978). Martin and Macoby (1983) expanded that style to four authoritative, authoritarian, indulgent and neglectful. These styles are the combinations of acceptance and responsiveness and of demand and control.

\section{Authoritative parenting}

Authoritative parenting is child centers approach. Authoritative parents always let the child serve the problem itself and are helpful these selves in solving the problem to their children. This parenting style is based on the parent child smooth interaction. If authoritative parents give punishment to their child they will explain the reason behind the punishment. Authoritative parents set limits for children to develop independence in their personality these parents take care of their children's

needs and forgive the mistakes of their children. This is done because child gets higher level of independence (Jackson and Hendrickson, 1998) 


\section{Authoritarian parenting style}

In this style the parents have higher expectations from their Childs. It is a constrained style of parenting. Authoritarian parents impose their will on their children forceful. They tell the child rules to spend the life. These parents do not have or have little mental interaction to communicate in the society. The children who are brought up with this parenting's style do not have self confidence. According to Eastern conventional child rearing are in practice of Asian, American families and if the rule are imposed more forceful upon the child, the child will become rebellious. Children of permissive parents are passionate and angry by mature. These types of children do not know how to control their temperament. But this fact is also to be noted that validity of these research approaches depends upon the situation and context and personal temperament of every child (Steinbery and Fletcher, 1994).

\section{Neglectful parenting}

Neglectful parent, do not take part in the activities of their children. These parents do not take care of the passions of their children. Neglectful parents provide all basic needs of life to their children but they do not support emotionally to their children.

\section{Disruptive behavior disorder}

The children who have disruptive behavior disorders normally break the laws during teen ages or when they were old two to three years. When children practice this behavior time and again they are suffering from a mental disorder which is called disruptive behavior disorder (Harris, 2006) The DSM-IV-TR relates the diagnosis of Conduct disorder as the mode of behavior in which normal rules of the society are neglected. The children who are patients of conduct disorder must have the following three points (i) aggression to people and animals, (ii) they destroy property, (iii) they seriously violate the rules of the society (American Psychological Association, 1994).

\section{Epidemiology of disruptive behavior}

The importance of disruptive behavior can be determined when it is the cause of medical warrant. There are some common traits which are found in parents (Macdonald, 2003) 


\section{Assessment of children with disruptive behavior}

Primary pediatric health care professionals cure for children with different levels of disruptive behaviors while the clinicians should study the behavior of the child that either the treatment of the parents is the motivator of this behavior. Parents mostly order their children like ago to your room these types of treatment create opposition in the temperament of the child. To avoid this negative behaviors of the child parents, give another order and this is what which negatively empower this behavior of the child. If the parents tell the reason of their order to the child, the response of the child may be positive. And if this is not done by the parents the child becomes use to go the oppositional behavior of the parents. If any of these child parents negotiations are perpetually used a consistent and bad temperament may develop (Forehand and McMahon, 1981).

\section{Risk factors for the development of disruptive behavior}

There are the four risk factors for the growth of disruptive behavior (i) Biological (ii) individual (iii) Family and (iv) social. Every factor is separate from other. It may be critical to growth of disruptive behavior (Burke, Lueber and Birmaher, 2002). Some of the most commonly cited risk factors include how socio-economic status; history of rejection and dysfunctional parenting (Jeffer, et al., 2005).

\section{Paterson's developmental model of antisocial behavior}

Patterson's coercion theory is one of the most vastly researched transitional motives describing the interaction between parenting and children's behavior. The model differentiates between the "early" and later starters in terms of the development of antisocial behavior. The children who have complex temperament are the example of the rude behavior of the parents. The misbehavior of the parents results in a continues antisocial temperament of the child (Lahey et al., 1999). Parents play important role for the development of children, due to the parent's negative attitude or behavior children can show the antisocial behavior. According to Peterson, in adolescents, the children can be developed disruptive behavior or conduct disorder. In middle childhood the children can be spoiled their academic career or refusal by peers. The parent's behavior, parental traits, socio-economic status, inheritance traits and demographic variables can more effect on early childhood. 


\section{Beisky's ecological model}

Patterson's proposes that interactions between children and parents are the major determinants of subsequent parent and child behavior, characteristics in Belskys model does not put such importance on children's. This model conceives that parenting perform are multiply indomitable by parents' individual resources. These factors can interact with each other and influence on parenting function, which were influences on child behavior. This model proposes to the influences of parent. More research concerning this manner has recommended that the consequence of adolescences characteristics on parenting behavior. This parenting style led to a focus on the influences of perceived child temperament as a moderator of the effects of ineffective parenting practices in the development and persistence of externalizing behavior problems (Bates, et al., 1999).

Chase (2013) portrays Attention-Deficit/Hyperactivity Disorder (ADHD) is a consistent, behavioral oversee issue, which is all the more consistently diagnose in youngsters. This is conceptualized customarily as a neurological issue; at the same time, there are numerous ecological components that impacts indication administration. Parental part is an essential component in practically every type of activity, so far the nitty gritty child rearing styles working by folks of young people with ADHD has gained little consideration. This exploration needed to address this issue through perceive companionships between child rearing styles, ADHD manifestations, and homework issues. The discoveries of this scientist demonstrate that definitive child rearing is not an unitary made, however it has numerous interpretations on a scale of requesting and responsive. The definitive child rearing style may help vicinity of indications of ADHD.

Ishak, Low, \& Lau, (2012) contended that folks impart an intelligent system, which offer stress to responsiveness as the more imperative trademark, are measured lenient folks. Folks who are careless and uninvolved in their kid's childhood a subtype of lenient child rearing, called separated. Definitive folks, be that as it may, incorporate an adjusted union of both responsiveness and requesting aspects in their child rearing strategy.

Leschied et al. (2008) speak to the finding of their inquiries about; these looks into coordinated with 38 studies, with what added up to 66,647 members. The consequences of this meta-dissection suggest that there are numerous indicators of withdrawn grown-up conduct; yet with these indicators are continuously raise in a nature's turf. Further indicators of 
reserved conduct incorporated "eyewitness roughness, between parental clash" and encountering "family stressors".

Fossum et al., (2007) his standard evaluation of 4 to 8 years of age youngsters 26 young ladies and 101 young men. On account of the depressive environment at home the kids enduring in troublesome conduct. The contrasts between young men and young ladies were few by seen folks. Anxiety level is more terrific in young ladies as contrasted with young men. Families and moms of young ladies showed up for larger amount of depressive side effects.

Gotlfried (1995) recommends proximal home environment contains the cognitive, social passionate and physical detailing accessible to Ehikhen in their family relationship. The analyst led their own particular longitudinal examination which concentrated on maternal business, family improvement and kids advancement.

Baumrind, (1966) portrayed definitive folks as folks who push "verbal correspondence for give and take," while tyrant folks were illustrate as insufficient to "adjusts, control, and survey the mentality and practices of the tyke". Baumrind, (1971) expressed that kids climb inside legitimate child rearing style participate in more "purposive conduct and free", as contrasted with tolerant and dictator child rearing style.

In today's life it has become very common to discuss the behaviors of parents and Adolescents. Children of modern life are very disturbed. Adolescents have this disruptive behavior especially against their parents or rules applied by their parents for understanding one thing, in the past we could not see this level of disruptive behavior of the Adolescents. Today's life is so fast that parents have not a single moment to understand feeling of the children then how an they condensate with their parents. The period of adolescents is very important. In this age reason of adolescents is that outer world is the source of attraction for the adolescence while parents try to teach morality. A parenting style is a psychological construct representing strategies that parents use in their child rearing. Disruptive behavior refers to any behavior that is hostile, destructive, and or violent. Generally, disruptive behavior has the potential to inflict injury or damage to the target person or object. Disruptive behavior includes physical assault, throwing objects, property destruction, self harming behaviors, and verbal threats. 


\section{Hypotheses}

1. There will be correlation between authoritarian parenting style and disruptive behavior among adolescents.

2. There will be correlation between authoritative parenting style and high disruptive behavior among adolescents.

3. There will be correlation between permissive parenting style and low disruptive behavior among adolescents.

4. Level of disruptive behavior will be higher in male adolescents as compared to female adolescents.

5. Level of disruptive behavior will be higher in rural adolescents as compared to urban adolescents.

\section{Method}

\section{Participants}

The sample is consisted of one hundred and twenty $(\mathrm{N}=120)$ adolescents sixty $(n=60)$ male and sixty $(n=60)$ female were taken from Multan city by using random sampling technique and the age group ranging is 13-19 years the result were also analysis by demographic variable i.e. (gender and residence). Along with the instruments, a demographical information sheet was attached in order to know about the demographic variables. The required information was age and gender.

\section{Instruments}

Two instruments were used in the present exploration (i) Parenting Style Scale was created by Jody Powel in 1998. Child rearing style scale was produced by Jody Powel and Pam Dillon of the Dayton In 1998. Child rearing style scale was comprised on 11 things every things had three alternatives each one demonstrating diverse style of child rearing. This scale has sufficient unwavering quality and dependability. Most noteworthy score shows predominant child rearing style (Powel. J., and Dillon. P., 1998) and (ii) Beck problematic conduct stock was created by Beck in 2005. Beck Young Stock the BYI were plan as self report instruments for surveying maladaptive insight and practices of kids ages 12-19. They incorporate uneasiness, dejection, troublesome conduct, annoyance and self idea. The complete stock comprised of 100 things, 80 things of rich were intended to evaluate the disguising troublesome conduct, while 20 things were utilized to survey the externalizing problematic conduct. The ivories were outline on 4 point Likert design. 
The score was total up to get the aggregate crude score. The score were changed over to t-score by matching. While being used in t-score table.

The test booklet comprised of two scales includes of parenting style and the disruptive behavior among adolescents was administered on the sample of 120 adolescents. Require demographic information was printed on a separate designed demographic sheet regarding age, gender and number of sibling, birth order and this was completed on family instruction for giving response to the items of the questionnaire sheet. The subjects were asked to respond to all the scale items according to the given instruction.

\section{Results}

Table 1

Correlation Between Authoritarian Parenting Style and Beck Disruptive Behavior $(N=120)$

\begin{tabular}{cc}
\hline \multicolumn{1}{c}{ Scale } & Disruptive behavior \\
\hline Authoritarian Parenting style & $.30^{* *}$ \\
\hline${ }^{*}<<0.05,{ }^{* *} p<.01$ &
\end{tabular}

Table 1 shows that there is a positive correlation between authoritarian parenting style with disruptive behavior among adolescence.

Table 2

Correlation Between Authoritative Parenting Style on the Scale of Beck Disruptive Behavior $(N=120)$.

\begin{tabular}{|c|c|}
\hline Scale & Disruptive behavior \\
\hline Authoritative Parenting style & $-.21 *$ \\
\hline
\end{tabular}

Table 2 shows that there is strongly negative significant correlation between authoritative parenting style and disruptive behavior among adolescence.

PESHAWAR JOURNAL OF PSYCHOLOGY AND BEHAVIORAL SCIENCES, 2018, VOL. 4, NO. 1, 1-13 
Table 3

Correlation Between Permissive Parenting Style on the Scale of Beck Disruptive Behavior $(N=120)$

\begin{tabular}{|c|c|}
\hline Scale & Disruptive behavior \\
\hline Permissive Parenting style & $-.18 *$ \\
\hline
\end{tabular}

Table 3 shows that there is slightly significant negative correlation between permissive parenting style with disruptive behavior among adolescence.

Table 4

Mean, Standard Deviation and t-Value for the Scores of Gender on the Scale of Beck Youth Inventory $(N=120)$.

\begin{tabular}{cccccc} 
Groups & $\mathrm{N}$ & Means & S.D & t-value & $\mathrm{P}$ \\
\hline Male & 60 & 67.08 & 7.84 & 3.92 & $0.003^{* *}$ \\
Female & 60 & 62.12 & 5.90 & &
\end{tabular}

$d f=118, p>0.05$, Cohen'sd $=0.71$

Table 4 shows that there is significant difference of disruptive behavior scale for the male and female. The p-value is 0.003 which shows that the level of disruptive behavior is higher in the male as compared to female.

Table 5

Mean, Standard Deviation and $t$-Value for the Scores of Residential Area on the Scale of Beck Youth Inventory $(N=120)$.

\begin{tabular}{cccccc}
\hline Groups & $\mathrm{N}$ & Means & S.D & t-value & $\mathrm{p}$ \\
\hline Urban & 60 & 65.09 & 7.54 & 0.86 & 0.94 \\
Rural & 60 & 63.92 & 7.08 & & \\
\hline
\end{tabular}

$d f=118, * p<.05$, Cohen's $\mathrm{d}=0.159$

Table 5 shows that there is no significance difference of disruptive behavior for the urban and rural adolescence. The p-value is 0.94 which 
shows that the level of disruptive behavior is higher in the urban as compared to rural adolescents.

\section{Discussion}

The present study aimed to explore the parenting style effect on adolescence behavior. Results stated that there is strongly negative significant correlation between the parenting styles and disruptive behavior among adolescent. Parenting styles integrate parents attitudes, beliefs and expectations for child behavior and thus persuade the framework in which parenting occurs e.g., authoritative styles versus authoritarian styles. In this argument, unless stated otherwise, parenting is used to refer to parental obedience and other behaviors that may transpire during parent-child exchanges. Several researches that examine the relationship between the parenting tracks portrayed in this segment and children's disruptive behavior. Scope of parental behavior which are important for children's development include: parental discipline in the form of limit-setting and control; instilling moral values, respect and concern for others; and involvement with children as teacher and play partner. Different dimensions of parenting are important at different times of development and in different contexts, depending upon children's needs and upon parental expectations about children's behavior.

First hypothesis designates that authoritarian parenting style is natively correlated with disruptive behavior. The result shows that the authoritarian parenting style is strongly natively correlated with disruptive behavior.

Second hypothesis indicates that authoritative parenting style is natively correlated with disruptive behavior. The result shows that that the authoritative parenting style is natively correlated with disruptive behavior.

Third hypothesis shows that permissive parenting style is natively correlated with disruptive behavior. The result shows that that the permissive parenting style is natively correlated with disruptive behavior.

Fourth hypothesis point out that disruptive behavior is high in male as compared to female. Mean, Standard Deviation and t- value for the score of male $(n=60)$ and female $(n=60)$ on the scale of Beck youth inventory. The result shows that parenting style in male and female adolescent. P-value of beck youth inventory is 0.003 so the results show that the disruptive behavior is significantly low in female as compare to male $(\mathrm{df}=180$, $\mathrm{p}<0.05)$.

PESHAWAR JOURNAL OF PSYCHOLOGY AND BEHAVIORAL SCIENCES, 2018, VOL. 4, NO. 1, 1-13 
Fifth hypothesis indicates that disruptive behavior is high in urban adolescent as compared to rural adolescent. Mean, Standard Deviation and $\mathrm{t}$ - value for the score of Urban $(n=60)$ and rural $(n=60)$ on the scale of Beck youth inventory. P-value is 0.940 so the results show that the disruptive behavior is significantly low in rural as compare to urban $(\mathrm{df}=180, \mathrm{p}>0.05)$.

In the present study, the perspective of all the circumstances it can be concluded that the significant effects of parenting style on the adolescent disruptive behavior. There is a negative correlation between parenting style and adolescent disruptive behavior. The level of disruptive behavior is elevated among male adolescent as measure up to female and it is also high in the adolescent belong to urban areas.

\section{Limitations}

1. The study has constrained assets and a vast specimen ought to be having involved with the end goal of the flow research. Throughout the procedure of this exploration work a few troubles were made in the extensive field work.

2. The specimen was about from particular school of Multan, these discoveries can't be summed up to the child rearing style as entirely.

3. During the information gathering process the analysts confront the obstacles from the respondents they were youthful.

4. Sample utilized as a part of the present study was little. It ought to be illustrative and huge enough to sum up the guidelines to the entire preadult.

\section{Recommendations}

More studies ought to be led on this issue on the grounds that it is critical to improve the familiarity with child rearing which could be useful in kid rising.

\section{References}

American Psychiatric Association; (1994). American Psychiatric Association. Diagnostic and Statistical Manual of Mental Disorders. 4th ed. Washington, DC:

Baumrind D. (1978). "Parental Disciplinary patterns and social competence in children". Youth soc.; 9 (3) 239-279. 
Baumrind, D. (1967). "Child care practices anteceding three patterns of Preschool Behavior". Genetic psychology Monographs, 75 (1), 43-88.

Baumrind, D., Larzelere, R.E., \& Owens, E.B. (2010). Effects of preschool parents' power assertive patterns and practices on adolescent development. Parenting: Science and Practice, 10, 157 - 201.

Burke JD, Loeber R, Birmaher B. (20020. Oppositional defiant disorder and conduct disorder: a review of the part 10 years, part II. Journal of American academic Child adolescents Psychiatry.;41(11):1275-1293

Feldman, R. (2005). Developmental Understating psychology, M. Graw-hill Company. London. 55, 218-232.

Forehand RL, McMahon RJ. (1981). Helping the Noncompliant Child: A Clinician's Guide to Parent Training. New York, NY: The Guilford Press; 1981

Fossum, S., Mørch, W.-T., Handegård, B. H. \&Drugli, M. B. (2007). Childhood disruptive behaviors and family functioning in clinically referred children: Are girls different from boys? Scandinavian Journal of Psychology, 48, 375-382.

Furedi, Frank. (2001). Paranoid Parenting: why ignoring the experts May be best for your child. Allen Lane. Pp. 240.

Gottfried, AE, Gottfried, AW \& Bathurst, K (1995). Maternal and dualearner employment, status and parentingee, in $\mathrm{MH}$ Bornstein, Handbook of Parenting, Vol. 2, Biology and Ecology of Parenting, Erlbaum : NJ.

Harris J. (2006). Disruptive behavior disorders. In: McMillan JA, Feigin RD, DeAngelis C, Jones MD, eds. Oski's Pediatrics: Principles \& Practice. 4th ed. Philadelphia, PA: Lippincott Williams \& Wilkins;629-634

Ishak, Z., Low, S.F., \& Lau, P.L. (2012). Parenting style as a moderator for students' academic achievement. Journal of Science Education and Technology, 21, $487-493$.

Jackson C. Henriksen L, Foshee Va. (1998). The authoritative parenting index; predicting health risk behaviors among children and adolescents. Health education behavior. 25 (3) 319-337.

Jaffee, SR. Caspi, A. Moffitt, T. et al. (2005). Nature x nurture: genetic vulnerabilities interact with physical maltreatment to promote conduct problems. Developmental Psychopathology; 17(1):67-84

Jason C. Hunt (2013). Associations between Different Parenting Styles and Child Behavior. PCOM Psychology Dissertations. Paper 262.

PESHAWAR JOURNAL OF PSYCHOLOGY AND BEHAVIORAL SCIENCES, 2018, VOL. 4, NO. 1, 1-13 
Kopko K. (2007). Parenting styles and adolescents. Ithaca, NY: Cornell University; 29 (2) 194-206.

Lahey BB, Schwab-Stone M, Goodman SH, et al. (2000). Age and gender differences in oppositional behavior and conduct problems: a crosssectional household study of middle childhood and adolescence. Journal of Abnormal Psychology; 109(3):488-503

Laskey, B.J. \& Cartwright-Hatton, S. (2009). Parental discipline behaviors and beliefs about their child: associations with child internalizing and mediation relationships. Child: Care, Health and Development, 35, $717-727$.

Maccoby E, Martin J. (1983). Socialization in the context of the family: parent child interaction In: Hetherington E, Ed. Handbook of child psychology: socialization, personality and social development. 29 (2) 194-206.

MacDonald EK. (2003). Principles of behavioral assessment and management. Pediatry Clinical North Am.; 50:801-816

Steinberg L., (1989). "Authoritative parenting, parenting, psychological maturity, and academic success among adolescent". 60 (6). 14241436

PESHAWAR JOURNAL OF PSYCHOLOGY AND BEHAVIORAL SCIENCES, 2018, VOL. 4, NO. 1, 1-13 